\title{
Early Spondyloarthritis Presenting as Premenopausal Osteoporosis and Multiple Vertebral Fractures: a Case Report
}

\author{
Liyanage $\mathrm{IK}^{* 1,2}$, Kottahachchi $\mathrm{DC}^{1,3}$, Navinan $\mathrm{R}^{1}$, Udumalagala $\mathrm{S}^{1}$, Rosa $\mathrm{C}^{1}$, Gunawardena $\mathrm{M}^{1}$, Thissera $\mathrm{T}^{1}$, \\ Karunarathna $\mathrm{S}^{1}$, Somasundaram $\mathrm{N}^{1}$ and Kulatunga $\mathrm{A}^{1}$ \\ ${ }^{1}$ National Hospital of Sri Lanka, Colombo, Sri Lanka \\ ${ }^{2}$ Department of Pharmacology, Faculty of Medical Sciences, University of Sri Jayewardenepura, Nugegoda, Sri Lanka \\ ${ }^{3}$ Department of Pharmacology, Faculty of Medicine, University of Kelaniya, Sri Lanka
}

*Corresponding author: Liyanage IK, National Hospital of Sri Lanka, Colombo and Department of Pharmacology, Faculty of Medical Sciences, University of Sri Jayewardenepura, Nugegoda, Sri Lanka, Tel: +94772339997, E-mail: isurujith@gmail.com

Citation: Liyanage IK, Kottahachchi DC, Navinan R, Udumalagala S, Rosa C, et al. (2018) Early Spondyloarthritis Presenting as Premenopausal Osteoporosis and Multiple Vertebral Fractures: a Case Report. J Case Rep Stud 6(6): 601. doi: 10.15744/2348-9820.6.601

Received Date: September 20, 2018 Accepted Date: December 29, 2018 Published Date: December 31, 2018

\begin{abstract}
We report a 30-year-old woman who presented during pregnancy with mechanical type backache due to non-traumatic multiple vertebral fractures. In depth assessment revealed multiple risk factors for osteoporosis, including adolescent steroid use for asthma, prolonged breastfeeding and vitamin D deficiency. She also had persistently elevated inflammatory markers with radiological evidence of early inflammatory sacro-ileitis. The rheumatoid factor and HLA B27 were negative. She was successfully managed with NSAIDS, zolindronic acid and calcium supplementation. This is an example of early inflammatory arthritis in the background of multiple risk factors causing osteoporosis severe enough to cause fragility fractures. This signifies the importance of screening for multiple risk factors in pre-menopausal osteoporosis even in the presence of one or two identified risk factors.
\end{abstract}

Keywords: Premenopausal Osteoporosis; Fragility Fractures; Inflammatory Spondyloarthritis; Vitamin D Deficiency

\section{Introduction}

Inflammatory arthritis including Rheumatoid Arthritis (RA) and Ankylosing Spondylitis (AS) are established risk factors for early osteoporosis [1,2]. Pathogenesis of osteoporosis in these patients is multifactorial, contributed by increased inflammatory cytokines (E.g. interleukene-6, tumor necrosis factor alfa), immobility, glucocorticoid treatment and clinically silent bowel disease [3].

\section{Case Report}

A 30-year-old lady, 2 weeks after the delivery of her second child presented with non-traumatic vertebral wedge fractures at multiple levels. She was referred to the medical ward for further investigations.

She had no ongoing medical problems and her first pregnancy was uncomplicated. She has electively delayed the second pregnancy for 8 years and used hormonal contraceptive methods. In her second pregnancy, she developed lower backache during early second trimester, which was initially attributed to the pregnancy itself. Retrospective symptom analysis revealed that she had morning stiffness lasting for 2 hours, severe nocturnal pain and pain on movements. These symptoms progressively worsened forcing her to be almost bedbound by the mid-3rd trimester. By this time, she developed a visible deformity of her back and she lost height.

She denied involvement of other joints, skin rashes or systemic symptoms of autoimmune rheumatic diseases. Her bowel habits were unaltered. On further inquiry into risk factors for osteoporosis, she revealed that she had childhood asthma and was given systemic steroids frequently. She took oral and inhalational preparations on and off from 8 years to 16 years of age. She breastfed her first child for 5 years. The only other medication she had taken was the oral contraceptive pill, which she took for 8 years.

On examination she had a visible kyphosis of the dorsal spine. She was in considerable pain. There were no other clinical features of nutritional deficiencies. She had multiple tender points along the spine and sacroiliac joints bilaterally. She had limited chest expansion $(2 \mathrm{~cm})$; modified Schober's test $3 \mathrm{~cm}$; occiput to wall distance of $18 \mathrm{~cm}$. Findings of investigations at presentation are summarized in Table 1. 


\begin{tabular}{|c|c|c|}
\hline Investigation & Value & Normal range \\
\hline White cell count $\left({ }^{*} 10^{3} / \mathrm{uL}\right)$ & 13.8 & $4.00-10.00$ \\
\hline Neutrophils (\%) & $82 \%$ & $50-70$ \\
\hline Lymphocytes (\%) & $16 \%$ & $20-40$ \\
\hline Eosinophils (\%) & $0.3 \%$ & $0.5-5$ \\
\hline Platelets $\left(10^{* 3} / \mathrm{uL}\right)$ & 393 & $150-400$ \\
\hline Haemoglobin $(\mathrm{g} / \mathrm{dL})$ & 12.0 & $11.0-16.0$ \\
\hline Erythrocyte sedimentation rate $\left(\mathrm{mm} / 1^{\text {st }}\right.$ hour $)$ & 97 & $<20$ \\
\hline C-Reactive Protein (mg/dl) & 35 & $<5$ \\
\hline $\operatorname{AST}(\mathrm{U} / \mathrm{L})$ & 15 & $10-35$ \\
\hline $\operatorname{ALT}(\mathrm{U} / \mathrm{L})$ & 13 & $10-40$ \\
\hline Albumin $(\mathrm{g} / \mathrm{L})$ & 38 & $36-48$ \\
\hline Globulin $(\mathrm{g} / \mathrm{L})$ & 39 & $22-40$ \\
\hline Total bilirubin (umol/L) & 8 & $5-21$ \\
\hline Alkaline phosphatase (U/L) & 217 & $100-360$ \\
\hline Ionized calcium $(\mathrm{mmol} / \mathrm{L})$ & 0.97 & $1.0-1.3$ \\
\hline Magnesium & 0.80 & $0.8-1.1$ \\
\hline Phosphorus & 0.80 & $0.8-1.5$ \\
\hline Para Thyroid Hormone (pg/mL) & 37.8 & $11-62$ \\
\hline Vitamin D level (ng/ml) & 18.98 & $50-70$ \\
\hline
\end{tabular}

Table 1: Key investigation findings

Contrast Enhanced Computer Tomography (CECT) of the spine showed osteopenia and multiple stable wedge fractures in the vertebral bodies at multiple levels (T8-T11) and erosions of the sacroiliac (SI) joints. This was compatible with chronic erosive sacroilitis. No other intra-abdominal pathology was noted in the CECT. These findings were confirmed by Magnetic Resonance Imaging (MRI) of the spine and SI joints. It also excluded involvement of the spinal cord. DEXA scan (performed using a HOLOGIC Discovery A S/N 80600 device (Hologic Inc., Waltham, MA) showed a Z score of -3.0 each in the lumbar vertebral area and -1.6 each in the hip joints.

She was further investigated for a cause of elevated inflammatory markers. The blood picture was suggestive of an inflammatory state with toxic changes in the neutrophils. Other cell lines were normal. Further investigations to exclude secondary inflammatory conditions and chronic infections were negative (Table 2).

\begin{tabular}{|c|c|}
\hline Investigation & Result \\
\hline Serum protein electrophoresis & Polyclonal gamma globulin band \\
\hline Anti Nuclear Antibody & negative \\
\hline Rheumatoid factor & negative \\
\hline Chest X ray & normal lung fields \\
\hline $\begin{array}{c}\text { Sputum for tuberculosis } \\
\text { Tuberculin skin sensitivity test }\end{array}$ & Microscopy (acid fast staining) and culture negative ${ }^{*}$ times, \\
\hline Urine full report and culture & Normal \\
\hline Blood culture & Increase in granulocyte precursors \\
\hline Bone marrow examination & Negative bacterial, fungal and tuberculosis culture \\
\hline Bone marrow culture & Negative \\
\hline STD screening (HIV, VDRL, TPHA) & Negative \\
\hline HLA B27 & Negative \\
\hline Brucella serology & Notice \\
\hline Table $2:$ Results of investigations
\end{tabular}

Table 2: Results of investigations to look for a secondary cause for osteoporosis

While in the ward she developed unilateral anterior uveitis. This responded to steroid eye drops prescribed after consultation with a specialist ophthalmologist. Recurrent episodes of uveitis did not occur and her vision was not affected.

She was treated with sulfasalazine, calcium-vitamin D supplements and zolendronic acid. She was advised to stop breastfeeding. She was prescribed a lumbar corset. Over a period of two months, her symptoms improved. Repeat DEXA scan performed using the same machine and technique in 6 months demonstrated improved bone mineral density (Z scores for lumbar vertebral area -2.4 and -1.3 for hip joints). 


\section{Discussion}

A secondary cause can be identified in almost two thirds of patients with premenopausal osteoporosis [4]. Common etiologies include use of drugs (steroids, anticonvulsants), endocrinopathies, nutritional deficiencies and chronic inflammatory conditions $[5,6]$. Depending on the age at onset and duration, these insults will result in either failure to achieve expected normal bone mass (low baseline bone mass) or loss of pre-formed or newly forming bone. In this patient there were multiple risk factors, acting in unison to produce severe osteoporosis.

Measuring Bone Mineral Density (BMD) using DEXA scan is the most widely used and standardized method for diagnosis of post-menopausal osteoporosis [7,8]. Although commonly used among post-menopausal women, DEXA scan is only indicated in special circumstances among premenopausal women. The indications include history of fragility fractures, having predisposing condition for secondary osteoporosis, or if treatment for osteoporosis is considered [7]. The patient in this case discussion was investigated due to presence of multiple fragility fractures.

The T-score obtained by DEXA scan can only be used for post-menopausal women and men over the age of 50 years [8]. In other categories of patients it is recommended to use the $\mathrm{Z}$ score (which indicates the BMD compared with age matched controls) [8].

The FRAX score is an algorithm developed by the World Health Organization to determine fracture risk due to osteoporosis. Although this was initially developed for post-menopausal women and men above the age of 50 years, it is currently validated for females and males between the ages 40-90 years. As our patient is not within this age group, FRAX score could not be applied [8].

Once low bone density is confirmed, especially in a pre-menopausal woman, further investigations are warranted to exclude secondary causes for osteoporosis. This is particularly applicable for patients with BMD Z score <-2.0 or has fragility fractures. A detailed history and examination can identify or exclude most of these conditions and can guide investigations [4]. This case report signifies the importance of carrying out a comprehensive evaluation even if one or more risk factors are identified early in the evaluation. The patient discussed in this case study, had multiple risk factors including possible low baseline bone density due to childhood steroid use, vitamin D deficiency and having a history of prolonged breastfeeding. Recent onset of inflammatory arthritis and pregnancy were the triggers that led to sudden deterioration. Although rare, pregnancy and breastfeeding itself can cause severe osteoporosis, especially in the presence of other risk factors $[9,10]$.

This patient had spondyloartritis with involvement of the sacroiliac joints and early involvement of the spine. Of the spondyloarthropathies, ankylosing spondylitis (AS) is well known to cause osteoporosis even in early or mild stage of the disease $[11,12]$. Although this patient did not have clear criteria to diagnose AS, this may be the initial presentation where her disease may later evolve into one of inflammatory arthropathies.

\section{Conclusion}

This case study is an example of early inflammatory arthritis presenting with pre-menopausal osteoporosis, severe enough to cause multiple vertebral fractures. Pre-menopausal Osteoporosis can be multi factorial and hence it is important to fully evaluate the patient even in the presence of one of more clearly identifiable risk factors. Treating all identified risk factors will facilitate a rapid response and prevention of further complications.

\section{References}

1. Roux C (2011) Osteoporosis in inflammatory joint diseases. Osteoporos Int 22: 421-33.

2. Mitra D, Elvins DM, Speden DJ, Collins AJ (2000) The prevalence of vertebral fractures in mild ankylosing spondylitis and their relationship to bone mineral density. Rheumatology 39: 85-9.

3. Magrey M, Khan MA (2010) Osteoporosis in Ankylosing Spondylitis. Curr Rheumatol Rep 12: 332-6.

4. Harper KD, Weber TJ (1998) Secondary osteoporosis: diagnostic considerations. Endocrinol Metab Clin North Am 27: 325-48.

5. Khosla S, Lufkin EG, Hodgson SF, Fitzpatrick LA, Melton LJ (1994) Epidemiology and clinical features of osteoporosis in young individuals. Bone 15: 551-5.

6. Cohen A, Shane E (2013) Evaluation and management of the premenopausal woman with low BMD. Curr Osteoporos Rep 11: 276-85.

7. Lewiecki EM, Gordon CM, Baim S, Leonard MB, Bishop NJ, et al. (2008) International Society for Clinical Densitometry 2007 adult and pediatric official positions. Bone 43: 1115-21.

8. Kling JM, Clarke BL, Sandhu NP (2014) Osteoporosis prevention, screening, and treatment: a review. J Womens Health 23: 563-72.

9. Abraham A, Cohen A, Shane E (2013) Premenopausal bone health: osteoporosis in premenopausal women. Clin Obstet Gynecol 56: 722-9.

10. Blanch J, Pacifici R, Chines A (1994) Pregnancy-associated osteoporosis: report of two cases with long-term bone density follow-up. Br J Rheumatol 33: 269-72.

11. Donnelly S, Doyle DV, Denton A, Rolfe I, McCloskey EV, et al. (1994) Bone mineral density and vertebral compression fracture rates in ankylosing spondylitis. Ann Rheum Dis 53: 117-21.

12. Will R, Palmer R, Bhalla AK, Ring F, Calin A (1989) Osteoporosis in early ankylosing spondylitis: a primary pathological event? The Lancet 334: 1483-5. 


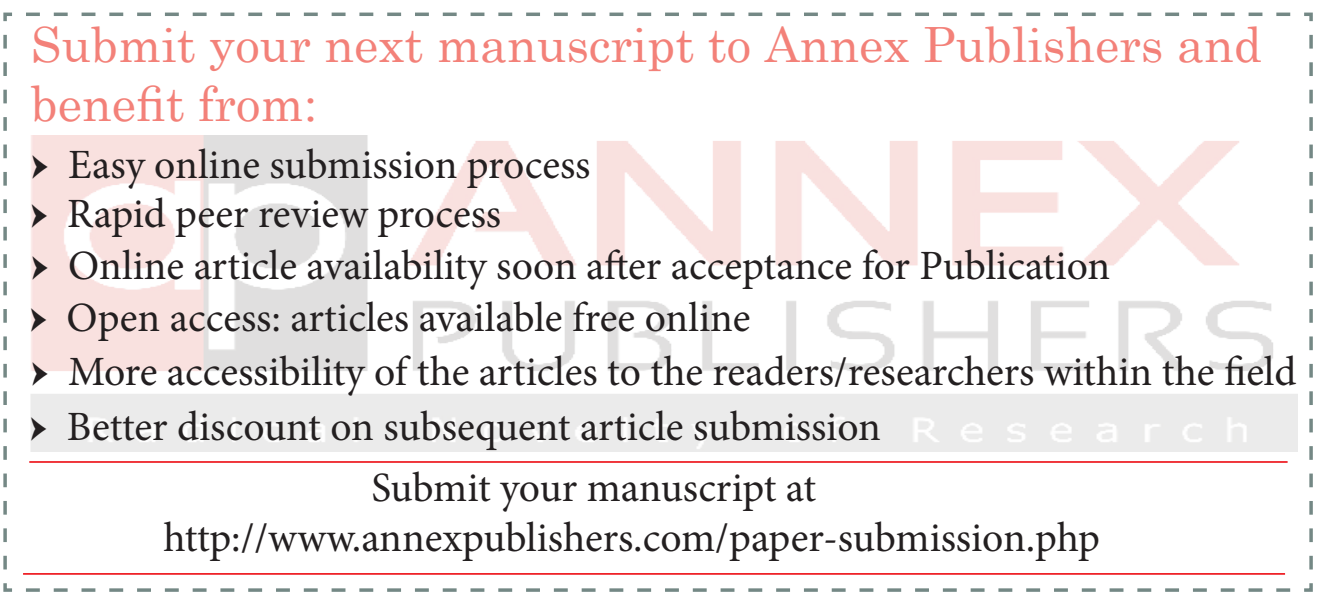

